\title{
Respiratory muscles in chronic obstructive pulmonary disease
}

\section{W. Fitting}

Division de pneumologie, Centre Hospitalier Universitaire Vaudois, Lausanne, Switzerland

\section{Introduction}

For a long time, the respiratory muscles have been neglected being considered as part of a simple "bellows" mechanism by physiologists and pulmonary physicians. Things have now markedly changed and research has been particularly active in this field over the past twenty years. The scientific community recognised the central importance of respiratory muscles in some diseases, particularly in neuromuscular disorders and in chronic obstructive pulmonary disease (COPD). This brief review is intended to summarise the current knowledge on respiratory muscle function in $\mathrm{COPD}$ and and its relevance for clinical practice.

Key words: respiratory muscles; diaphragm; obstructive lung disease; emphysema

\section{Respiratory muscle load}

During quiet breathing the inspiratory muscles are active, whereas the expiratory muscles are recruited only with increased ventilation, increased load, and for coughing. In COPD, the inspiratory muscles face an elevated load for several reasons (figure 1). Although airflow limitation is more pronounced during expiration, the airway resistance is increased during inspiration as well. The inspiratory muscles also face an increased elastic load because of a reduced dynamic compli-

\section{Figure 1}

Mechanisms leading to an imbalance between respiratory muscle load ( $\left.P_{\text {breath }}\right)$ and capacity $\left(P_{\max }\right)$ in COPD.
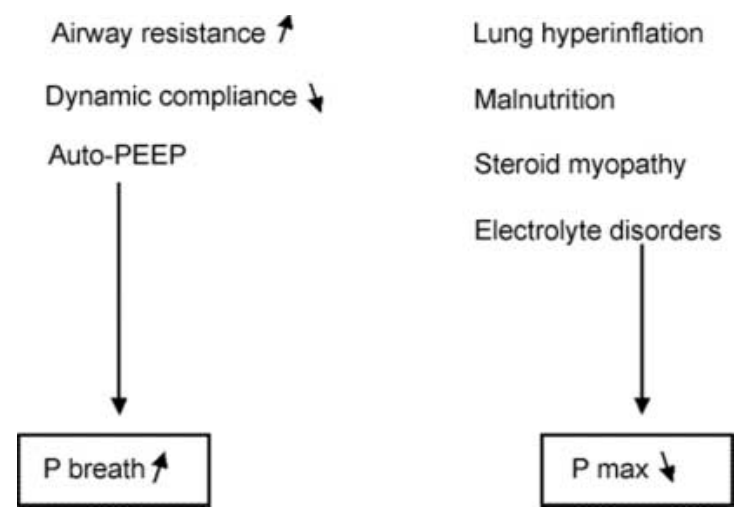

ance, the lungs being stiffer than normal during breathing. Finally, in cases of severe airflow limitation, the time required to empty the lungs is far greater than the time available for expiration. In other words, the patient initiates the next inspiration before reaching the normal end-expiratory lung volume, i.e. functional residual capacity (FRC). This increase in FRC due to incomplete expiration is called "dynamic hyperinflation". As lung emptying is not fully terminated at end-expiration, a residual positive pressure remains in the airways which has been termed "intrinsic positive end-expiratory pressure" (intrinsic PEEP or autoPEEP) $[1,2]$. Before initiating inspiration, the patient has to generate a negative pressure equal to the auto-PEEP in order to reverse the direction of airflow. Thus, auto-PEEP represents an additional load for the inspiratory muscles. In stable patients, the auto-PEEP is only a few $\mathrm{cm} \mathrm{H}_{2} \mathrm{O}$, but it can increase considerably if tidal volume or breathing frequency increase, or if airflow limitation becomes more severe. For all these reasons, the patient with COPD must generate a higher than normal inspiratory pressure at each breath $\left(\mathrm{P}_{\text {breath }}\right)$.

\section{Respiratory muscle capacity}

In COPD, lung hyperinflation is caused by two mechanisms: static hyperinflation is due to loss of the lungs elastic recoil (emphysema), and dynamic hyperinflation results from incomplete lung emptying as mentioned above. The diaphragm, which is a mobile structure, is profoundly affected by lung hyperinflation, becoming shorter than normal. Like all skeletal muscles, the diaphragm is 
governed by the length-tension relationship: at a certain length, ie, at optimal length, the diaphragmatic muscles filaments of actin and myosin are in an optimal relationship and the tension is maximal for a given neural activation. If the muscle is working at a shorter length, the tension produced is much less for the same level of neural activation [3]. The reduced length of the diaphragm mainly affects the part which is cranio-caudally oriented and apposed to the lower rib cage, the so-called "zone of apposition". Because the diaphragm works like a piston, a shorter zone of apposition implies a shorter range of motion, independent of the effect on maximal tension. Furthermore, the zone of apposition may in part disappear if the diaphragm flattens, with the consequence that the muscle fibers pull the ribs in an expiratory rather than inspiratory direction [4].
In COPD, respiratory muscle capacity may be impaired by additional mechanisms. COPD patients are frequently undernourished [5] and their diaphragmatic muscle mass is reduced in even greater proportion than their body weight [6]. Furthermore, corticosteroids are still often used on a long term basis in COPD despite their well known adverse effects. Steroid myopathy may develop in respiratory and peripheral muscles even at relatively low doses [7, 8]. Electrolyte disturbances affect skeletal muscle function and should be checked for in acutely ill patients.

These different mechanisms explain the reduced capacity of inspiratory muscles in COPD, which translates into a lower maximal pressure $\left(\mathrm{P}_{\max }\right)$.

\section{Consequences of load/capacity imbalance}

The inspiratory muscles in COPD are therefore characterised by an imbalance between load and capacity, as reflected by an increased $\mathrm{P}_{\text {breath }} / \mathrm{P}_{\max }$ ratio. If a skeletal muscle contracts above a certain proportion of its maximal force, the contraction cannot be maintained because of fatigue. In 1977, Roussos and Macklem [9] tested the hypothesis of diaphragmatic fatigue in humans. Healthy volunteers breathed mainly with their diaphragm against different inspiratory resistances while their transdiaphragmatic pressure $\left(\mathrm{P}_{\mathrm{di}}\right)$ was measured with oesophageal and gastric balloon-catheters. They were able to breathe indefinitely when the ratio Pdi/Pdi max was $<0.4$, but their endurance was limited when the ratio was set above this critical threshold. Fatigue could be induced separately in the diaphragm and in rib cage muscles according to the breathing pattern, the critical threshold being 0.6 when breathing mainly with rib cage muscles $[10,11]$. Thus, respiratory muscle fatigue could easily be induced experimentally in volunteers submitted to breathing against resistances. It was hypothesised that COPD patients, due to their naturally increased $\mathrm{P}_{\text {breath }} / \mathrm{P}_{\text {max }}$ ratio, develop respiratory muscle fatigue during exacerbations leading to ventilatory failure and hypercapnia. However, in part because of methodological difficulties, it has not been possible to prove overt respiratory muscle fatigue in these circumstances. At present, it is considered more likely that patients adopt by reflex a pattern of rapid shallow breathing to decrease Pbreath. Thus, rapid shallow breathing would represent a way to avoid respiratory muscle fatigue, at the expense of hypercapnia [12]. The mechanism of this adaptive reflex is not known, but dyspnoea may be involved because this sensation is clearly related to the $\mathrm{P}_{\text {breath }} / \mathrm{P}_{\max }$ ratio and to the neural drive directed to inspiratory muscles $[13,14]$.

\section{Therapeutic options}

Smoking cessation is beneficial at any stage of COPD and should be a priority therapeutic goal [15]. With regard to respiratory muscles, whatever the actual role of fatigue, the imbalance between load and capacity seems to be essential in the genesis of dyspnoea and in the development of ventilatory failure. The different therapeutic options available to the clinician to correct this imbalance are summarised here (figure 2).

\section{Pharmacotherapy}

Although airflow limitation is by definition little influenced by drugs in COPD, this approach should not be neglected. Inhaled bronchodilators, anticholinergics and $\beta_{2}$-agonists, are indicated for any symptomatic patient. Even a small decrease in airway resistance is beneficial and reduces the required inspiratory effort $\left(\mathrm{P}_{\text {breath }}\right)$. Furthermore, it is important to note that the inhalation of bronchodilators often has a larger effect on lung volumes than on expiratory flows in COPD. Thus, a marked fall of functional residual capacity may occur with only a small or barely significant improvement in $\mathrm{FEV}_{1}$. Such a reduction of hyperinflation translates into an improvement of diaphragmatic strength $\left(\mathrm{P}_{\max }\right)$. Theophylline has a limited bronchodilator effect and additionally has a small inotropic effect on the diaphragm. However, this drug is not systematically recommended in COPD because of its various adverse effects and 
its narrow therapeutic range. During exacerbations, oral corticosteroids have a favourable effect on $\mathrm{FEV}_{1}$, and thereby likely on respiratory muscle load/capacity imbalance. This translates into a reduced treatment failure rate and a shorter length of hospitalisation. This effect is obtained with prednisone $30 \mathrm{mg} /$ day for 2 weeks [16]. Longer corticosteroid therapy should be avoided, in particular because of the risk of steroid myopathy.

\section{Lung volume reduction surgery (LVRS)}

In case of severe hyperinflation due to emphysema, preferentially of the heterogeneous type, resecting the most affected lung areas offers an interesting palliation with reduction of hyperinflation, and improvement of spirometry and exercise tolerance for a year or more. As can be expected, the reduction of airflow limitation unloads the inspiratory muscles, in particular via a marked decrease in auto-PEEP [17]. By reducing hyperinflation LVRS helps restore a more physiological length and shape of the diaphragm and thereby improves its maximal strength [18]. The end result is a significant reduction of the $\mathrm{P}_{\text {breath }} / \mathrm{P}_{\max }$ ratio [19] and of the neural drive to the diaphragm $[20,21]$.

\section{Ventilatory support}

In patients with acute or chronic respiratory failure, noninvasive mechanical ventilation via a nasal or a facial mask immediately reduces the activation and the work of inspiratory muscles and provides relief of dyspnoea [22, 23]. The role of long term non-invasive ventilation in COPD is still uncertain, but a subgroup of severely hypercapnic patients seems to benefit from this therapy. It has been hypothesised that regular nocturnal ventilatory support could improve inspiratory muscle strength, but this has not been consistently demonstrated and alternative mechanisms probably play a greater role.

\section{Exercise training}

Respiratory rehabilitation and its main component exercise training are now accepted as a key therapeutic approach to improve dyspnoea, quality of life and exercise tolerance in patients with COPD [24,

\section{Figure 2}

Therapeutic options aiming at the correction of imbalance between respiratory muscle load $\left(P_{\text {breath }}\right)$ and capacity $\left(P_{\max }\right)$ in COPD.
25]. By improving aerobic capacity, general exercise training reduces ventilatory needs and thereby decreases the load faced by inspiratory muscles [26].

\section{Respiratory muscle training}

In view of the reduced capacity of inspiratory muscles in COPD, the idea of training respiratory muscles specifically is appealing. Three main techniques can be used: breathing against an inspiratory resistance, breathing against an inspiratory threshold load, and normocapnic hyperpnoea. Provided that the stimulus is strong enough, there is no doubt that respiratory muscle training increases inspiratory muscle strength and endurance. However, after more than 20 years of research, it has not been consistently demonstrated that this is associated with improvement in dyspnoea, quality of life and exercise tolerance $[27,28]$. Further studies are still needed to better define both the methodology to be used and the categories of patients susceptible to benefit from respiratory muscle training.

Some recent studies may help explain why training is less successful for respiratory muscles than for peripheral muscles in COPD. Using phrenic nerve stimulation, it was shown as expected that the diaphragm of COPD patients generates less pressure than that of normal subjects. However, considering the hyperinflation, it was found that, at similar lung volumes, the diaphragm of COPD patients was in fact able to generate slightly higher than normal pressures [29]. This observation may be explained by an adaptive process to chronic shortening of the diaphragm. Previous animal studies had shown that the number and length of diaphragm sarcomeres dropped in experimental emphysema and this phenomenon was recently demonstrated in biopsies of the diaphragm in patients with COPD [30]. Such an adaptation could help maintain a normal strength despite a shorter operational length. Another factor is the level of neural activation of the diaphragm. In contrast to a long held belief, electrophysiological studies show that the diaphragm is more activated in patients with COPD, even with hypercapnia, than in normal subjects [31]. If the diaphragm is chronically contracting at a higher level, one may hypothesise that it is submitted to a spontaneous training effect. Two recent studies support this hypothesis. Diaphragmatic biopsies in patients with COPD showed an increased density of mitochondria [30] and a shift in muscle fibres with an increase in type I (slow-twitch, oxidative) and a decrease in type II (fast-twitch, glycolytic) fibres [32]. This pattern is typical of endurance training and contrasts with opposite findings in peripheral muscles showing deconditioning in these patients. Thus, the relative lack of beneficial effect of respiratory muscle training in COPD may be explained by their spontaneous training. The altered geometry of the diaphragm, with a shorter range of motion, also prevents a gain in strength to be transformed into a significant gain in volume displacement. 


\section{Conclusion}

COPD represents a model of respiratory muscle dysfunction, mainly because of lung hyperinflation. Intensive research has confirmed the central role of this dysfunction in the genesis of dyspnea and respiratory failure. However, the perception of this problem has slightly changed over the years. First, the imbalance between load and capacity seems to play a pivotal role in itself rather than via the development of overt muscle fatigue. Second, the apparent weakness of the diaphragm is essentially due to lung hyperinflation. This muscle ap- pears to be trained by chronic overload, in sharp contrast with limb muscles which are typically deconditioned by sedentarity in these patients.
Correspondence:
Prof. 7. W. Fitting
Division de pneumologie
CHUV
CH-1011 Lausanne
E-mail:jfitting@chuv.hospvd.ch

\section{References}

1 Pepe PE, Marini JJ. Occult positive end-expiratory pressure in mechanically ventilated patients with airflow obstruction. Am Rev Respir Dis 1982;126:166-70.

2 Rossi A, Gottfried SB, Zocchi L, Higgs BD, Lennox S, Calverley PMA, et al. Measurement of static compliance of the total respiratory system in patients with acute respiratory failure during mechanical ventilation: the effect of intrinsic positive endexpiratory pressure. Am Rev Respir Dis 1985;131:672-7.

3 Smith J, Bellemare F. Effect of lung volume on in vivo contraction characteristics of human diaphragm. J Appl Physiol 1987; 62:1893-900.

4 Cassart M, Pettiaux N, Gevenois PA, Paiva M, Estenne M. Effect of chronic hyperinflation on diaphragm length and surface area. Am J Respir Crit Care Med 1997;156:504-8.

5 Schols AMWJ, Soeters PB, Dingemans AMC, Mostert R, Frantzen PJ, Wouters EFM. Prevalence and characteristics of nutritional depletion in patients with stable COPD eligible for pulmonary rehabilitation. American Review of Respiratory Disease 1993;147:1151-6.

6 Thurlbeck WM. Diaphragm and body weight in emphysema. Thorax 1978;33:483-7.

7 Decramer M, Lacquet LM, Fagard R, Rogiers P. Corticosteroids contribute to muscle weakness in chronic airflow obstruction. Am J Respir Crit Care Med 1994;150:11-6.

8 Decramer M, de Bock V, Dom R. Functional and histologic picture of steroid-induced myopathy in chronic obstructive pulmonary disease. Am J Respir Crit Care Med 1996;153:1958-64.

9 Roussos CS, Macklem PT. Diaphragmatic fatigue in man. J Appl Physiol 1977;43:189-97.

10 Fitting JW, Bradley TD, Easton PA, Lincoln MJ, Goldman MD, Grassino A. Dissociation between diaphragmatic and rib cage muscle fatigue. J Appl Physiol 1988;64:959-65.

11 Zocchi L, Fitting JW, Majani U, Fracchia C, Rampulla C, Grassino A. Effect of pressure and timing of contraction on human rib cage muscle fatigue. Am Rev Respir Dis 1993; 147:857-64.

12 Bégin P, Grassino A. Chronic alveolar hypoventilation helps to maintain the inspiratory muscle effort of COPD patients within sustainable limits. Chest 2000;117:271S-3S.

13 Bradley TD, Chartrand DA, Fitting JW, Killian KJ, Grassino A. The relation of inspiratory effort sensation to fatiguing patterns of the diaphragm. Am Rev Respir Dis 1986;134:1119-24.

14 Leblanc P, Bowie DM, Summers E, Jones NL, Killian KJ. Breathlessness and exercise in patients with cardiorespiratory disease. Am Rev Respir Dis 1986;133:21-5.

15 Scanlon PD, Connett JE, Waller LA, Altose MD, Bailey WC, Buist AS, et al. Smoking cessation and lung function in mild-tomoderate chronic obstructive pulmonary disease. The Lung Health Study. Am J Respir Crit Care Med 2000;161:381-90.

16 Davies L, Angus RM, Calverley PMA. Oral corticosteroids in patients admitted to hospital with exacerbations of chronic obstructive pulmonary disease: a prospective randomised controlled study. Lancet 1999;354:456-60.
17 Tschernko EM, Wisser W, Wanke T, Rajek MA, Kritzinger M, Lahrmann $\mathrm{H}$, et al. Changes in ventilatory mechanics and diaphragmatic function after lung volume reduction surgery in patients with COPD. Thorax 1997;52:545-50.

18 Teschler H, Stamatis G, El-Raouf Farhat AA, Meyer FJ, Costabel U, Konietzko N. Effect of surgical lung volume reduction on respiratory muscle function in pulmonary emphysema. Eur Respir J 1996;9:1779-84.

19 Laghi F, Jubran A, Topeli A, Fahey PJ, Garrity ER, Arcidi JM, et al. Effect of lung volume reduction surgery on neuromechanical coupling of the diaphragm. Am J Respir Crit Care Med 1998;157:475-83.

20 Celli BR, Montes de Oca M, Mendez R, Stetz J. Lung reduction surgery in severe COPD decreases central drive and ventilatory response to $\mathrm{CO}_{2}$. Chest 1997;112:902-6.

21 Lahrmann H, Wild M, Wanke T, Tschernko E, Wisser W, Klepetko W, et al. Neural drive to the diaphragm after lung volume reduction surgery. Chest 1999;116:1593-600.

22 Carrey Z, Gottfried SB, Levy RD. Ventilatory muscle support in respiratory failure with nasal positive pressure ventilation. Chest 1990;97:150-8.

23 Polese G, Viatacca M, Bianchi L, Rossi A, Ambrosino N. Nasal proportional assist ventilation unloads the inspiratory muscles of stable patients with hypercapnia due to COPD. Eur Respir J 2000;16:491-8.

24 Lacasse Y, Wong E, Guyatt G, King D, Cook D, Goldstein R. Meta-analysis of respiratory rehabilitation in chronic obstructive pulmonary disease. Lancet 1996;348:1115-19.

25 American Thoracic Society. Pulmonary Rehabilitation - 1999. Am J Respir Crit Care Med 1999;159:1666-82.

26 Casaburi R, Patessio A, Ioli F, Zanaboni S, Donner CF, Wasserman K. Reductions in exercise lactic acidosis and ventilation as a result of exercise training in patients with obstructive lung disease. Am Rev Respir Dis 1991;143:9-18.

27 Smith K, Cook D, Guyatt GH, Madhavan J, Oxman AD. Respiratory muscle training in chronic airflow limitation: a metaanalysis. Am Rev Respir Dis 1992;145:533-9.

28 Berry MJ, Adair NE, Sevensky KS, Quinby A, Lever HM. Inspiratory muscle training and whole-body reconditioning in chronic obstructive pulmonary disease. A controlled randomized trial. Am J Respir Crit Care Med 1996;153:1812-6.

29 Similowski T, Yan S, Gauthier AP, Macklem PT, Bellemare F. Contractile properties of the human diaphragm during chronic hyperinflation. N Engl J Med 1991;325:917-23.

30 Orozco-Levi M, Gea J, Lloreta JL, Félez M, Minguella J, Serrano $S$, et al. Subcellular adaptation of the human diaphragm in chronic obstructive pulmonary disease. Eur Respir J 1999;13: 371-8.

31 De Troyer A, Leeper JB, McKenzie DK, Gandevia SC. Neural drive to the diaphragm in patients with severe COPD. Am J Respir Crit Care Med 1997;155:1335-40.

32 Levine S, Kaiser L, Leferovich J, Tikunov B. Cellular adaptations in the diaphragm in chronic obstructive pulmonary disease. N Engl J Med 1997;337:1799-806. 
The many reasons why you should choose SMW to publish your research

What Swiss Medical Weekly has to offer:

- SMW's impact factor has been steadily rising, to the current 1.537

- Open access to the publication via the Internet, therefore wide audience and impact

- Rapid listing in Medline

- LinkOut-button from PubMed with link to the full text website http://www.smw.ch (direct link from each SMW record in PubMed)

- No-nonsense submission - you submit a single copy of your manuscript by e-mail attachment

- Peer review based on a broad spectrum of international academic referees

- Assistance of our professional statistician for every article with statistical analyses

- Fast peer review, by e-mail exchange with the referees

- Prompt decisions based on weekly conferences of the Editorial Board

- Prompt notification on the status of your manuscript by e-mail

- Professional English copy editing

- No page charges and attractive colour offprints at no extra cost

\section{Impact factor Swiss Medical Weekly}

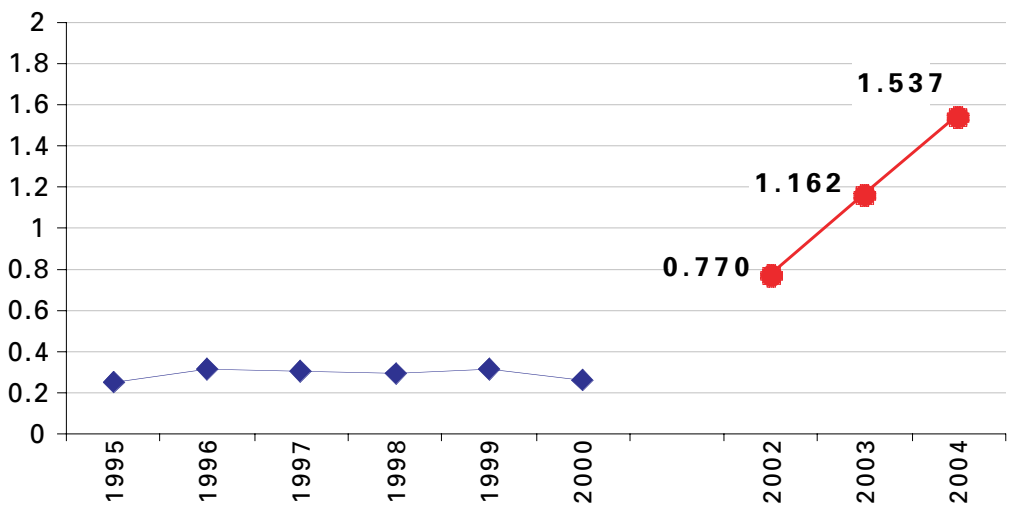

— Schweiz Med Wochenschr (1871-2000)

- Swiss Med Wkly (continues Schweiz Med Wochenschr from 2001)
Editorial Board

Prof. Jean-Michel Dayer, Geneva

Prof. Peter Gehr, Berne

Prof. André P. Perruchoud, Basel

Prof. Andreas Schaffner, Zurich

(Editor in chief)

Prof. Werner Straub, Berne

Prof. Ludwig von Segesser, Lausanne

International Advisory Committee

Prof. K. E. Juhani Airaksinen, Turku, Finland

Prof. Anthony Bayes de Luna, Barcelona, Spain

Prof. Hubert E. Blum, Freiburg, Germany

Prof. Walter E. Haefeli, Heidelberg, Germany

Prof. Nino Kuenzli, Los Angeles, USA

Prof. René Lutter, Amsterdam,

The Netherlands

Prof. Claude Martin, Marseille, France

Prof. Josef Patsch, Innsbruck, Austria

Prof. Luigi Tavazzi, Pavia, Italy

We evaluate manuscripts of broad clinical interest from all specialities, including experimental medicine and clinical investigation.

We look forward to receiving your paper!

Guidelines for authors:

http://www.smw.ch/set_authors.html

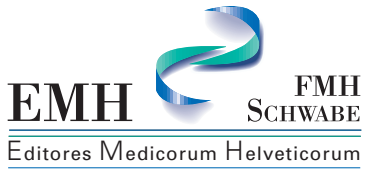

All manuscripts should be sent in electronic form, to:

EMH Swiss Medical Publishers Ltd.

SMW Editorial Secretariat

Farnsburgerstrasse 8

CH-4132 Muttenz

Manuscripts:

Letters to the editor:

Editorial Board:

Internet: submission@smw.ch

letters@smw.ch red@smw.ch http://www.smw.ch 